\title{
Adsorption of Organic Dyes from Aqueous Solution by Surfactant Modified Corn Straw
}

\author{
C. Umpuch and B. Jutarat
}

\begin{abstract}
The modification of adsorbent with a cationic surfactant is an effective and inexpensive method to enhance sorption capability of adsorbent. In this study, raw corn straw, modified with a cationic surfactant, tetradecyltrimethyl ammonium bromide was used as adsorbent for dye removal from aqueous solution. The modification caused surface properties of the adsorbent altered from hydrophilic to hydrophobic. To comprehend the modification, the physical property of adsorbents was characterized by BET surface analysis, FTIR-spectra and SEM images. The adsorption of two organic dyes namely blue21 and yellow 20 on the modified adsorbent has been investigated in three batch adsorption experiments. Firstly, kinetic study was performed. It was found that the equilibrium time was at $180 \mathrm{~min}$ and the kinetic data obeyed pseudo-second order kinetic model. Secondly, the effect of the pH solution was investigated. It was found that the adsorption capacity decreased at a low level with increase in the solution pH. Finally, the adsorption isotherms experiment was conducted and the equilibrium adsorption data was fitted into Langmuir and Freudlich isotherms and the system followed only the Freulich equation. From the above result, the corn straw modified by cationic surfactant is an effective adsorbent for removal of the organic dyes from aqueous solution.
\end{abstract}

Index Terms-Adsorption, organic dyes, surfactant, corn straw.

\section{INTRODUCTION}

Thai government has promoted the idea to people in rural area to gather into groups to develop production of their local products since 2006. This project is known as "ONE TAMBON ONE PRODUCT" project and the products are also called "OTOP" products. Locals can earn additional income from the production of their products in trading aside from their main source of income from agriculture. The textile process in household scale is one of the most rapid growing industries since the handmade textile products, for example, silk and cotton fabrics are greatly valued by Thai and foreign customers. Although there are many natural dyes available, the ingrain colored by those dyes are not bright and durable. Therefore, the villagers usually color their products with chemical dyes. The chemical dyes are cheap and readily available. The chemical dyes do not only produce the brighter color but they are also resistant to light, heat and biological degradation. These characteristics provisions persuaded

Manuscript received April 5, 2013; revised May 25, 2013.

C. Umpuch is with the Department of Chemical Engineering, Faculty of Engineering and the National Center of Excellence of Environmental and Hazardous Waste Management, Ubon Ratchathani University, Ubon Ratchathani 34190 Thailand (e-mail: umpuch_ck@yahoo.com).

B. Jutarat was with the Department of Chemical Engineering, Faculty of Engineering, Ubon Ratchathani University, Ubon Ratchathani 34190 Thailand (e-mail:sai130130@hotmail.com). villagers to use chemical dyes over natural ones. On the other hand, the staining process usually uses a lot of water and colored effluents are also produced from this process. The wastewater is usually dumped under the house or near water resources without treatment. Since the chemical dyes are durable to light, heat and biodegradation, the accumulation of the chemical dyes in natural water resources causes the water to be polluted, unattractive and can be harmful to aquatic life. Thereby, it is important to treat colored wastewater before discharge. The treatment method for such wastewater should be simple and low in cost and can also be independently operated and managed the village group.

There are many techniques to removing dye from the wastewater including physical, biological and chemical techniques. Although the biological and chemical methods provide high dye removal efficiency, they also generate by-products which need post-treatment [1]. Adsorption is a physico-chemical process that is simple and inexpensive. The agriculture residues can be developed to be an adsorbent in order to adsorb dye, heavy metal and pollutants etc [2]. Corn straw is left in fields after harvest and consists of stalk and husk. It is abundant in Thailand every year so and corn straw is used as adsorbent in this research.

Furthermore, the natural adsorbent can improve their adsorption capacity through various modifications. The treatment with surfactant is one of effective modifications. The cationic surfactant modified adsorbent alters the surface property of the adsorbent from hydrophilicity to hydrophobicity or organophilicity [3]. The modified adsorbent enhances their adsorption capacity for dye in synthetic wastewater. For example, the surfactant modified coconut coir pith yielded adsorption capacity of $76.3 \mathrm{mg} / \mathrm{g}$ and $14.9 \mathrm{mg} / \mathrm{g}$ for Direct Red 12B and Rhodamine B, respectively [4]. The surfactant modified adsorbent in this work is called "organo-corn straw".

The study was undertaken to evaluate the effectiveness of organo-corn straw in the removal of two organic dyes such as blue 21 and yellow 20 by adsorption. The batch tests were conducted to study the kinetic and equilibrium adsorption behaviors. The effect of solution $\mathrm{pH}$ was also studied.

\section{MATERIALS AND METHODS}

\section{A. Materials}

Raw corn straw samples and two chemical dyes manufactured by a Thai factory including blue 21 and yellow20 were purchased from a local market near Ubon Ratchathani University, Warinchamrap District, Ubon Ratchathani, Thailand. The surfactant agent used was tetradecyltrimethylammonium bromine (Merck, Germany) which was quaternary amine surfactant. 


\section{B. Preparation of Adsorbents}

Raw corn straw was washed twice with distillated water and then dried at $40{ }^{\circ} \mathrm{C}$ until weight constant and then crushed and passed through 50 mesh sieve to obtain particle size below $300 \mu \mathrm{m}$.

The pretreated corn straw sample was used for the organo-corn straw preparation. $1.0 \mathrm{~g}$ of the pretreated adsorbent sample was added into an Erlenmeyer flak containing $100 \mathrm{~mL}$ of $1000 \mathrm{mg} / \mathrm{L}$ tetradecyltrimethyl ammonium bromide solution. The suspension was agitated with $200 \mathrm{rpm}$ for $15 \mathrm{~min}$ at $25^{\circ} \mathrm{C}$. Afterwards, the modified adsorbent was removed by vacuum filtration with GF80 filter (Whatman, UK) and then the sample was dried at $40{ }^{\circ} \mathrm{C}$ until weight constant and then crushed and passed through 50 mesh sieve to obtain particle size below $300 \mu \mathrm{m}$.

All adsorbents were packed in the plastic bag and stored in the desiccator for further use.

\section{Adsorbent Characterization}

The precursor and the modified adsorbent were characterized by various physical apparatus such as Automatic Surface Analyzer, FTIR-spectroscopy and Scanning Electron Microscopy (SEM).

\section{Adsorbent selection and Batch Experiments}

The adsorbent selection was evaluated from the percent dye removal of the both adsorbents. $1.0 \mathrm{~g}$ of the adsorbent was loaded into $100 \mathrm{ml}$ of $100 \mathrm{mg} / \mathrm{L}$ dye solution and then horizontally shaken for 24 hours. The removal percentages of blue 21 and yellow 20 by the raw corn straw were $58.72 \%$ and $62.54 \%$, respectively while the surfactant modified corn straw were $94.70 \%$ and $95.67 \%$ for blue 21 and yellow 21 , respectively. It is obvious that the percentage of dye removal of the organo-corn straw is much higher than that of the untreated adsorbent. Therefore, the only organo-corn straw was used for further experiments.

The batch tests were classified into 3 parts. Firstly, the kinetic experiment was investigated. $0.1 \mathrm{~g}$ of the adsorbent was loaded into an Erlenmeyer flask containing $100 \mathrm{ml}$ of $200 \mathrm{mg} / \mathrm{L}$ dye solution and then horizontally shaken at 200 $\mathrm{rpm}$. The sample was collected at a time interval of 5 to 360 min. Secondly, the adsorption isotherm experiment of dye adsorption was performed. $0.1 \mathrm{~g}$ of the adsorbent was loaded into $100 \mathrm{ml}$ of 50 to $250 \mathrm{mg} / \mathrm{L}$ dye solution and horizontally shaken at $200 \mathrm{rpm}$ for 24 hours. Finally, the effect of solution $\mathrm{pH}$ was studied. $0.1 \mathrm{~g}$ of the adsorbent was loaded into $100 \mathrm{ml}$ of $200 \mathrm{mg} / \mathrm{L}$ dye solution and adjusted the $\mathrm{pH}$ among 2.0 to 10.0 by $0.01 \mathrm{~N} \mathrm{NaOH}$ and/or $0.01 \mathrm{M} \mathrm{HCl}$ and then horizontally shaken at $200 \mathrm{rpm}$ for 24 hours.

\section{E. Analytical Method}

The collected samples of batch experiments was first vacuum filtration with $\mathrm{GF} / \mathrm{C}$ filter (Whatman, $\mathrm{UK}$ ) to remove the adsorbent. Then, free adsorbent solution was analyzed by a UV-Vis Spectrophotometer to determine the remaining dye concentration. The maximum absorption wavelength of blue 21 and yellow20 was $476 \mathrm{~nm}$ and $535 \mathrm{~nm}$, respectively.

\section{F. Kinetic Models}

In order to predict the adsorption mechanisms related to dye adsorption on the adsorbent, the kinetic data are usually fitted by the kinetic models such as pseudo-first order and pseudo-second order models. The pseudo-first order model, proposed by Lagergren [5] was expressed in form

$$
d q t / d t=k_{1}\left(q_{e}-q_{t}\right)
$$

where $q_{e}$ and $q_{t}$ are the adsorption capacity $(\mathrm{mg} / \mathrm{g})$ of dye at equilibrium and at a time $t$, respectively, and $k_{1}$ is the rate constant for pseudo-first order adsorption ( $1 / \mathrm{min})$. After integration and applying initial condition which is $q_{t}=0$ at $t=$ 0, Equation (1) becomes

$$
\ln \left(q_{e}-q_{t}\right)=\ln q_{e^{-}} k_{1} t
$$

The best fit of kinetic data to the Equation (2) revealing that the external mass transfer through a boundary layer is the rate of limiting step.

The pseudo second order equation proposed by Ho [6] can be written as:

$$
d q t / d t=k_{2}\left(q_{e}-q_{t}\right) 2
$$

where $k_{2}$ is the rate constant for pseudo-second order adsorption (g/(mg.min)). For the initial condition which is $q_{t}$ $=0$ at $t=0$, the integrated form of equation (3) becomes

$$
1 /\left(q_{e}-q_{t}\right)=1 / q_{e}+k_{2} t
$$

The best fit of kinetic data to the equation (4) indicating that the forming of interaction between adsorbate and adsorbent on the external surface of adsorbent is the rate of limiting step.

\section{G. Isotherm Models}

The adsorption isotherms developed by Langmuir and Freudlich [7] were commonly used to fit the equilibrium data with different equilibrium dye concentration. The isotherms that predict adsorption behavior can be used to design the sorption system. Langmuir isotherm is related to the sorption taking place at specific homogeneous sites within the adsorbent. Freundlich isotherm is based on the assumption that a heterogeneous surface with a non-uniform heat distribution of the sorption along the surface. The linear equations of Langmuir (Equation (5)) and Freundlich isotherm (Equation (6)) are shown below:

$$
C_{e} / q_{e}=C_{e} / q_{m}+1 /\left(K L \cdot q_{m}\right)
$$

where $q_{m}$ is monolayer capacity or limiting sorption $(\mathrm{mg} / \mathrm{g})$ and $K_{L}$ is Langmuir constant $(\mathrm{L} / \mathrm{mg})$. The parameters can be evaluated from the slope and intercept of the linear plot of $C_{e} / q_{e}$ against $C_{e}$.

$$
\ln q_{e}=\ln K_{f}+1 / n \ln C_{e}
$$

where $K_{f}$ is Freundlich characteristic constant $(\mathrm{mg} / \mathrm{g})(\mathrm{L} / \mathrm{g})^{1 / n}$ and $1 / n$ is the heterogeneity factor of adsorption. The parameters obtained from intercept and slope of $\ln q_{e}$ versus $\ln C_{e}$ of the linear plot respectively. 


\section{RESULTS AND DISCUSSIONS}

\section{A. Dyes and Adsorbent Characterizations}

The chemical compositions of the blue 21 and yellow 20 are listed in Table I. The main chemical compositions of the blue20 and yellow21 were carbon. The carbon content of blue 21 is approximately twice as high than that of the yellow20. The difference of carbon content can affect the adsorption capacity of organic substances on the organophilic adsorbent [8].

TABLE I: CHEMICAL COMPOSITION OF BLUE21 AND YELLOW20

\begin{tabular}{|l|l|l|l|l|}
\hline \multirow{2}{*}{ Dye } & \multicolumn{4}{|c|}{ Chemical composition } \\
\cline { 2 - 5 } & $\% \mathrm{C}$ & $\% \mathrm{H}$ & $\% \mathrm{~N}$ & $\% \mathrm{~S}$ \\
\hline Blue21 & 21.21 & 0.63 & 0.88 & 3.47 \\
\hline Yellow20 & 12.73 & 0.38 & 0.92 & 4.81 \\
\hline
\end{tabular}

The BET surface area of the untreated corn straw and the organo-corn straw were 7.29 and $4.21 \mathrm{~m}^{2} / \mathrm{g}$, respectively. The coating of cationic surfactant molecule on the precursor surface causes pore blocking. The lower BET surface area of the modified adsorbent is due to a loss in internal surface area. It is well documented that the coating of surfactant on an adsorbent surface generates a lower specific surface area in the modified adsorbent [3].

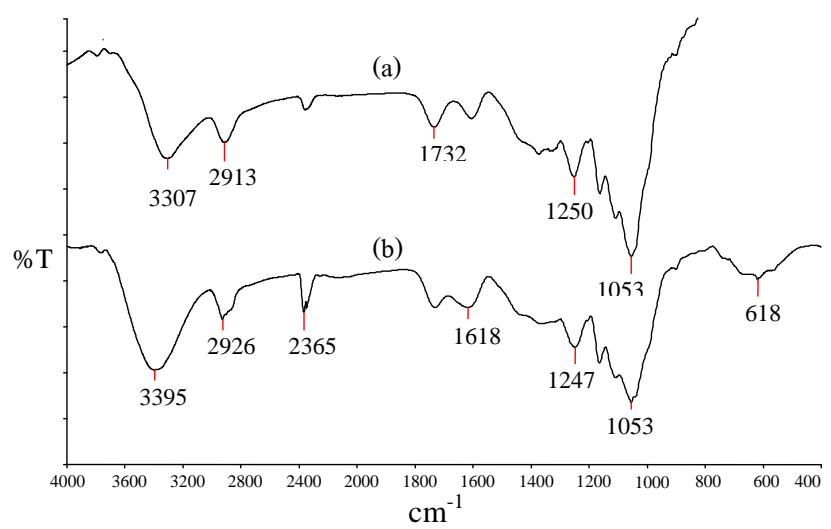

Fig. 1. IR-spectra of corn straw (a) and organo-corn straw (b)

Fig. 1 shows the IR spectra of corn straw and organo-corn straw. It was observed that the IR spectra of the raw corn straw has vibration bands representing hydrophobic functional groups such as $\mathrm{C}-\mathrm{H}$ at $2,926 \mathrm{~cm}^{-1}, \mathrm{C} \equiv \mathrm{C}$ or $\mathrm{N} \equiv \mathrm{N}$ at $2,326 \mathrm{~cm}^{-1}$ [9]. After modification, the displacement of a vibration band from 3307 to $3395 \mathrm{~cm}^{-1}$ denoting that the $\mathrm{N}-\mathrm{H}$ stretching amines replaced the $\mathrm{O}-\mathrm{H}$ stretching or $\mathrm{H}$-bonded and the additional peak at $673 \mathrm{~cm}^{-1}$ indicating the C-C bonding existed. Since the cationic surfactant studied composed of amine and carbon chain, the appearance of those functional groups confirms the binding between the precursor and the surfactant. This reveals that the hydrophobic-hydrophobic interaction can be the main interaction for the organo-corn straw and the surface properties of adsorbent altering from hydrophilic to hydrophobic.

Fig. 2 shows the SEM images of corn straw (Fig. 2a) and organo-corn straw (Fig. 2b). It can be observed that the external surface of corn straw contains only a few pores and ridges on the edge. On the other hand, the external surface of the organo-corn straw was covered by a thin film. The coating of cationic surfactant on the surface causes disappearance of the ridge on the edge which was observed in the raw corn straw image. The fracture on the organo-corn straw surface is due to the uncompleted coating of the surfactant. The difference of the morphology of the both adsorbent confirms the cationic surfactant molecules adhering on the external surface of the untreated corn straw.

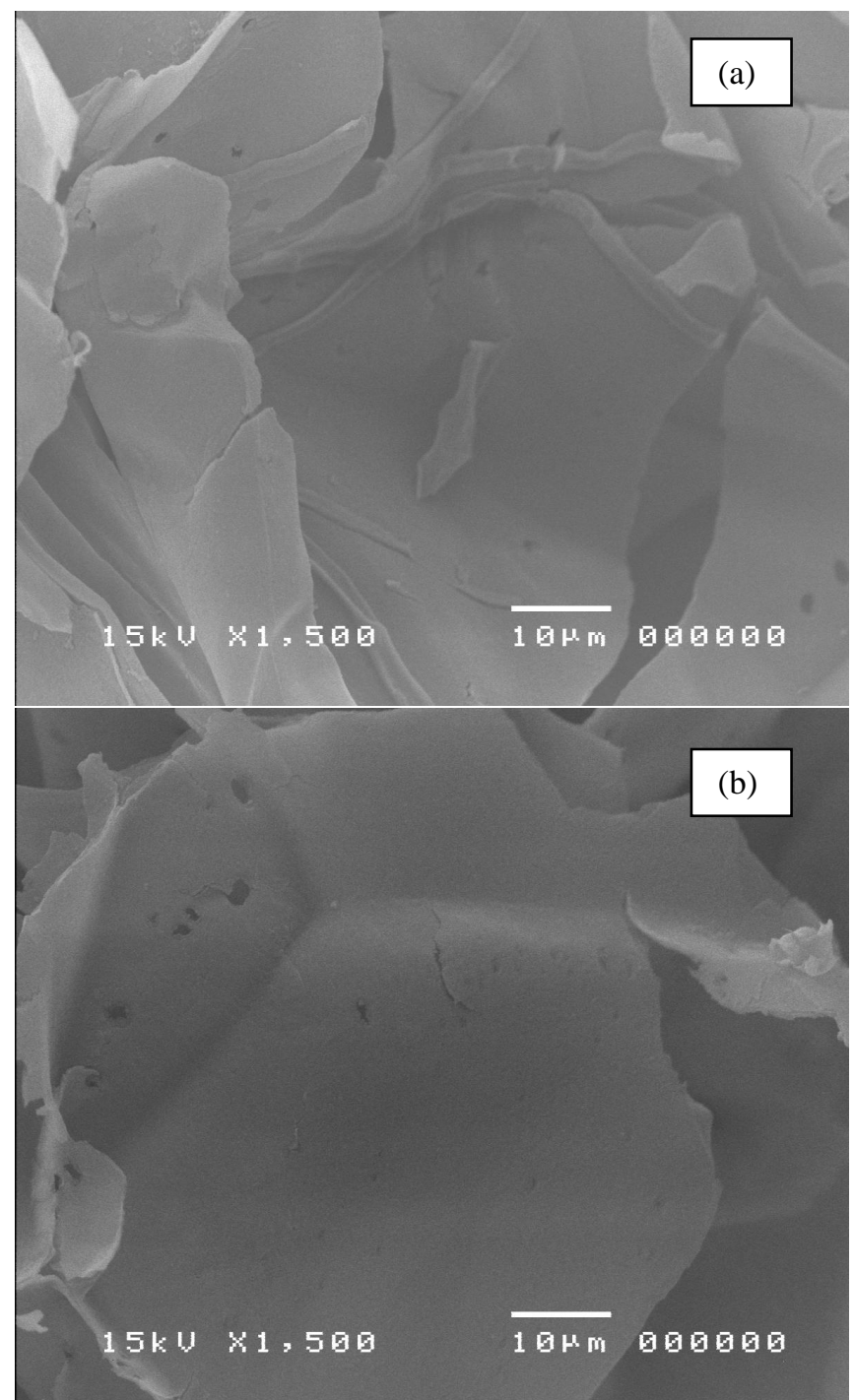

Fig. 2. SEM image IR-spectra of corn straw (a) and organo-corn straw (b)

\section{B. Effect of Contact Time on the Removal of Dye}

The influence of contact time on the dye uptake from the aqueous solution was depicted in Fig. 3. It can be observed that the adsorption capacity of the dye on the organo-corn straw rapidly increased in the first 10 minutes and maintained a slower increase until constant at $180 \mathrm{~min}$ (equilibrium time). In the rapid sorption rate in the initial stages, it can be described that there was an abundant availability of active sites on the organo-corn straw external surface so the dye adsorbed on the surface easily and quickly. The slower rate in the later stage was due to dye being diffused into the interior of the adsorbent because the external surface had been occupied by the dye molecules. After 180 minutes, the sorption rate was totally constant because the adsorbent had already saturated with the dye and attained equilibrium stage. To ensure the equilibrium, the other experiments were left for 24 hours.

The adsorption capacity of bule 21 is higher than that of 
yellow20. Because the bule21 dye molecule has higher carbon content than that of yellow20 (see Table I), the hydrophobic-hydrophobic interaction between the blue 21 and the organo-corn straw is stronger than that of the yellow20 [10].

\section{Effect of Initial Dye Concentration}

The effects of the initial dye concentration in dye removal from aqueous solution have been illustrated in Fig. 4. It was observed that the amount of blue 21 dye concentration adsorbed on the organo-corn straw had a linear increase with the increase in the initial dye concentration. The linear increase was attributed to the adsorption ability of the adsorbent and had not been attained with the blue21 dye molecules or organo-corn straw can still absorb the blue 21 molecule even though the initial dye concentration was higher than $250 \mathrm{mg} / \mathrm{L}$. On the other hand, the yellow20 uptake initial increased and then was almost constant at initial dye concentration of $250 \mathrm{mg} / \mathrm{L}$. The adsorbent had mostly saturated with yellow 20 at this initial concentration.

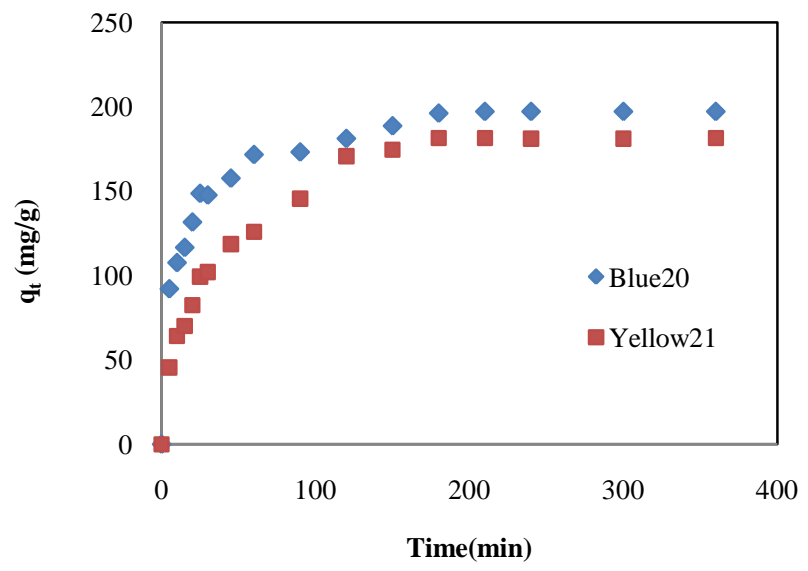

Fig. 3. Effect of contact time on the dye uptake on organo-corn straw

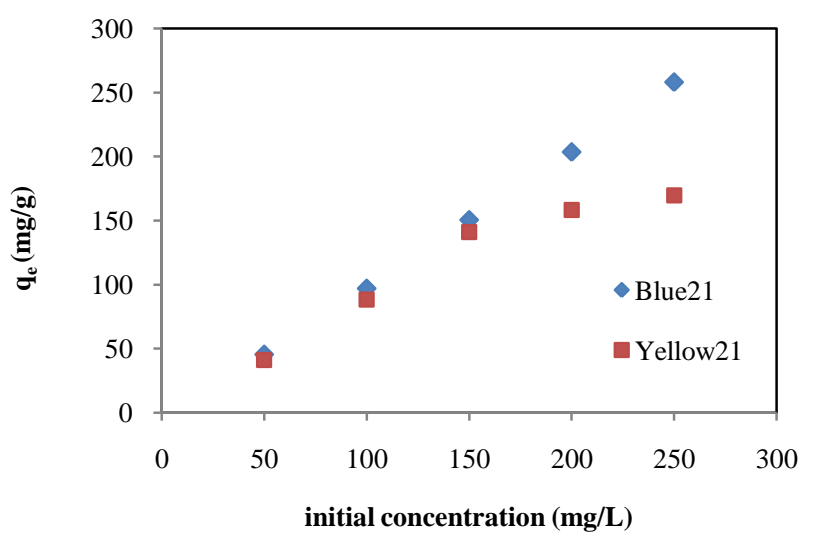

Fig. 4. Effect of initial dye concentration on the dye uptake on organo-corn straw

\section{Effect of Solution $p H$}

The adsorption capacity of blue 21 and yellow 20 onto the organo-corn straw had steady low decrease levels with increase in the solution $\mathrm{pH}$ as depicted in Fig.5. The small decrease is probably attributed to the dissociation of functional groups of blue 21 and yellow20 with the $\mathrm{pH}$ solution. The dyes and the conjugated bases are of different hydrophobicity. Hence, the dye uptakes partitioned to the organo-corn straw should be little $\mathrm{pH}$ dependent.

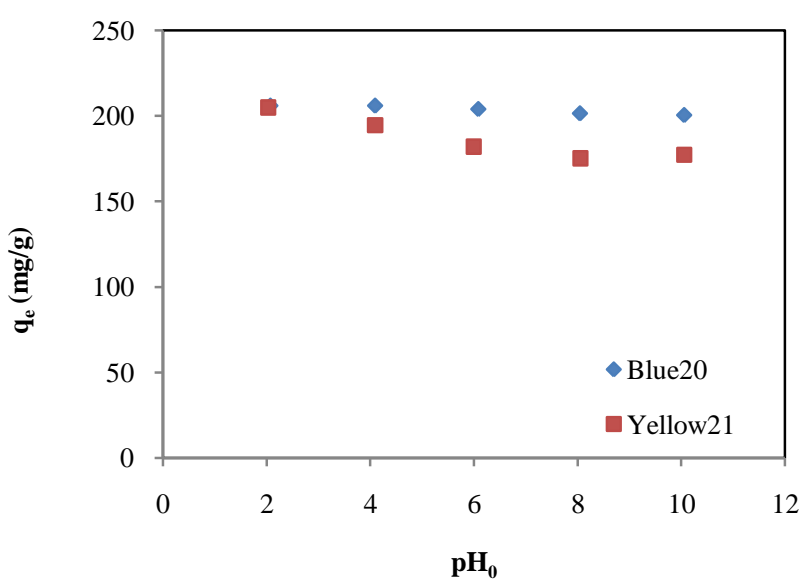

Fig. 5. Effect of initial pH solution on the dye uptake on organo-corn straw

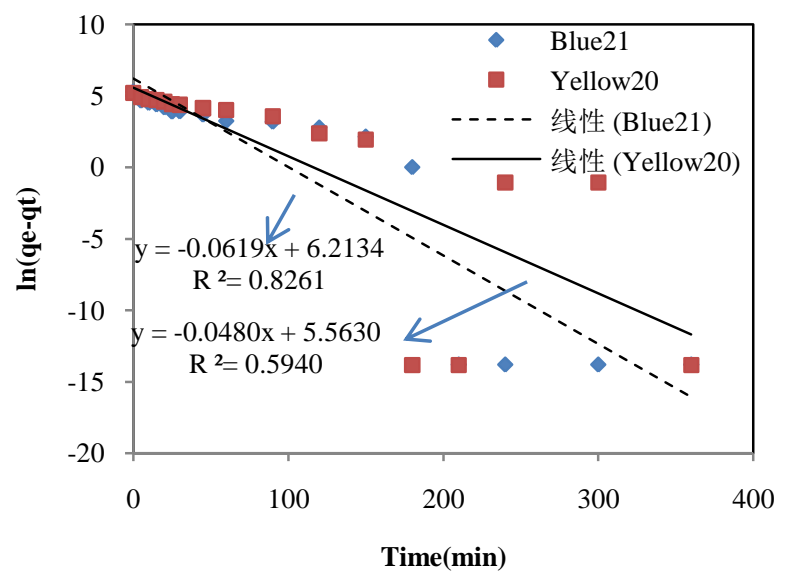

Fig. 6. Pseudo-first order kinetic model for blue21 and yellow20 adsorbed on organo-corn straw

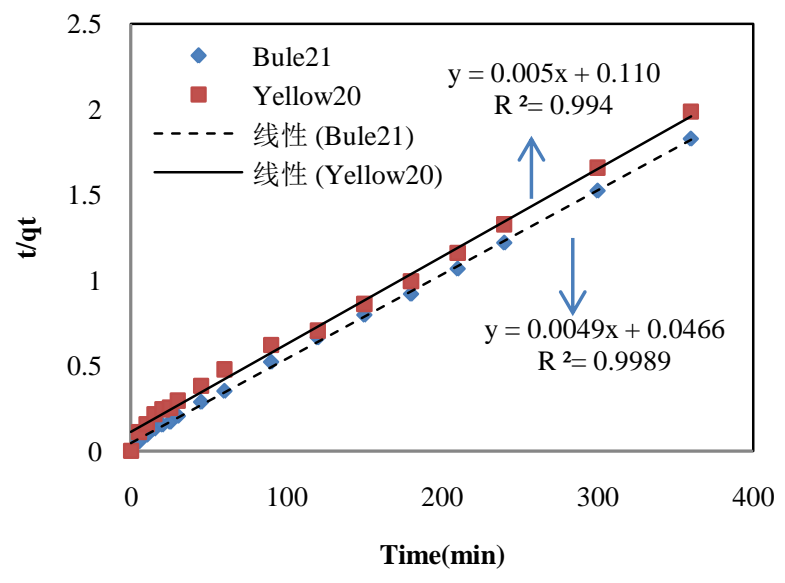

Fig. 7. Pseudo-Second order kinetic model for blue21 and yellow20 adsorbed on organo-corn straw

\section{E. Kinetics Models}

The kinetic data that were fitted by the pseudo-first and pseudo-second order kinetic models are shown in Fig. 6 and Fig. 7, respectively. Poor correlation of the equilibrium data with the pseudo-first order kinetic model was observed. Normally, the pseudo-first order equation was well fitted for the data obtained at the beginning of the batch experiment. A good correlation between the kinetic data and the pseudo-second order equation was found. The hydrophobic-hydrophobic interactions between dye 
molecules and the adsorbent were formed at external surface of the adsorbent. This step takes the longest time duration compared to other steps, also known as the rate of limiting step.

The parameters of the kinetic models and the correlation coefficients are given in Table II. The results showed that the kinetic data were well described by the pseudo-second order $\left(r^{2}=0.9774\right)$ indicating chemical sorption that had taken place on the surface of the organo-corn straw which was the rate of limiting step. The chemical sorption could be involved the adsorption process.

TABLE II: PSEUdO-FIRST ORDER, PSEUdO-SECOND ORDER PARAMETERS FOR BLUE21 AND YELLOW20 ADSORBED ON THE ORGANO-CORN STRAW

\begin{tabular}{|c|c|c|}
\hline Model & parameter & value \\
\hline \multicolumn{3}{|c|}{ Blue21 } \\
\hline & $q_{e}(\exp )\left(\mathrm{mg} \cdot \mathrm{g}^{-1}\right)$ & 197.00 \\
\hline \multirow[t]{3}{*}{ Pseudo-first order } & $k_{l}\left(\min ^{-1}\right)$ & 0.0217 \\
\hline & $q_{e}(\mathrm{cal})\left(\mathrm{mg} \cdot \mathrm{g}^{-1}\right)$ & 87.99 \\
\hline & $r^{2}$ & 0.9012 \\
\hline \multirow[t]{3}{*}{ Pseudo-second order } & $k_{2}\left(\mathrm{~g} \cdot \mathrm{mg}^{-1} \cdot \mathrm{min}^{-1}\right)$ & 0.000515 \\
\hline & $q_{e}(\mathrm{cal})\left(\mathrm{mg} \cdot \mathrm{g}^{-1}\right)$ & 204.08 \\
\hline & $r^{2}$ & 0.9989 \\
\hline \multicolumn{3}{|c|}{ Yellow20 } \\
\hline & $q_{e}(\exp )\left(\mathrm{mg} \cdot \mathrm{g}^{-1}\right)$ & 188.38 \\
\hline \multirow[t]{3}{*}{ Pseudo-first order } & $k_{1}\left(\min ^{-1}\right)$ & 0.0204 \\
\hline & $q_{e}(\mathrm{cal})\left(\mathrm{mg} \cdot \mathrm{g}^{-1}\right)$ & 156.73 \\
\hline & $r^{2}$ & 0.9744 \\
\hline \multirow[t]{3}{*}{ Pseudo-second order } & $k_{2}\left(\mathrm{~g} \cdot \mathrm{mg}^{-1} \cdot \mathrm{min}^{-1}\right)$ & 0.000235 \\
\hline & $q_{e}(\mathrm{cal})\left(\mathrm{mg} \cdot \mathrm{g}^{-1}\right)$ & 196.08 \\
\hline & $r^{2}$ & 0.9949 \\
\hline
\end{tabular}

TABLE III: ISOTHERM CONSTANTS AND CORRELATION COEFFICIENTS FOR BLUE21 AND YELLOW20 ADSORPTION ON THE ORGANO-CORN STRAW

\begin{tabular}{|c|c|c|}
\hline Model & parameter & value \\
\hline \multirow{3}{*}{ Langmuir isotherm } & $q_{\max }\left(\mathrm{mg} \cdot \mathrm{g}^{-1}\right)$ & -96.15 \\
\cline { 2 - 3 } & $K_{L}\left(\mathrm{~L} \cdot \mathrm{g}^{-1}\right)$ & 7.72 \\
\cline { 2 - 3 } & $r^{2}$ & 0.6170 \\
\hline Freundlich isotherm & $K_{f}\left(\mathrm{mg}^{1-1 / n} \cdot \mathrm{L}^{1 / n} \cdot \mathrm{g}^{-1}\right)$ & 2.043 \\
\cline { 2 - 3 } & $n$ & 0.4617 \\
\cline { 2 - 3 } & $r^{2}$ & 0.8726 \\
\hline \multirow{2}{*}{ Langmuir isotherm } & $r_{\max }\left(\mathrm{mg} \cdot \mathrm{g}^{-1}\right)$ & 434.78 \\
\cline { 2 - 3 } & $K_{L}\left(\mathrm{~L} \cdot \mathrm{g}^{-1}\right)$ & 15.97 \\
\cline { 2 - 3 } & $r^{2}$ & 0.7545 \\
\hline \multirow{2}{*}{ Freundlich isotherm } & $K_{f}\left(\mathrm{mg}^{1-1 / 1 / n} \cdot \mathrm{L}^{1 / n} \cdot \mathrm{g}^{-1}\right)$ & 18.33 \\
\cline { 2 - 3 } & $n$ & 1.27 \\
\cline { 2 - 3 } & $r^{2}$ & 0.9147 \\
\hline
\end{tabular}

\section{F. Adsorption Isotherms}

The adsorption isotherms of blue 21 and yellow20 which are a relationship between $\mathrm{q}_{\mathrm{e}}$ and $\mathrm{C}_{\mathrm{e}}$ were plotted in Fig. 8 . The adsorption capacity of the blue 21 increases linearly due to two possibly reasons; (1) the adsorption ability of adsorbent has not completed with the blue21 (see Fig.4) and (2) the sorbed dye molecules can accompany themselves to form a multilayer on the adsorbent surface. Because the adsorbent has mostly saturated with yellow20, the adsorption capacity initially increases and then treads to be constant.

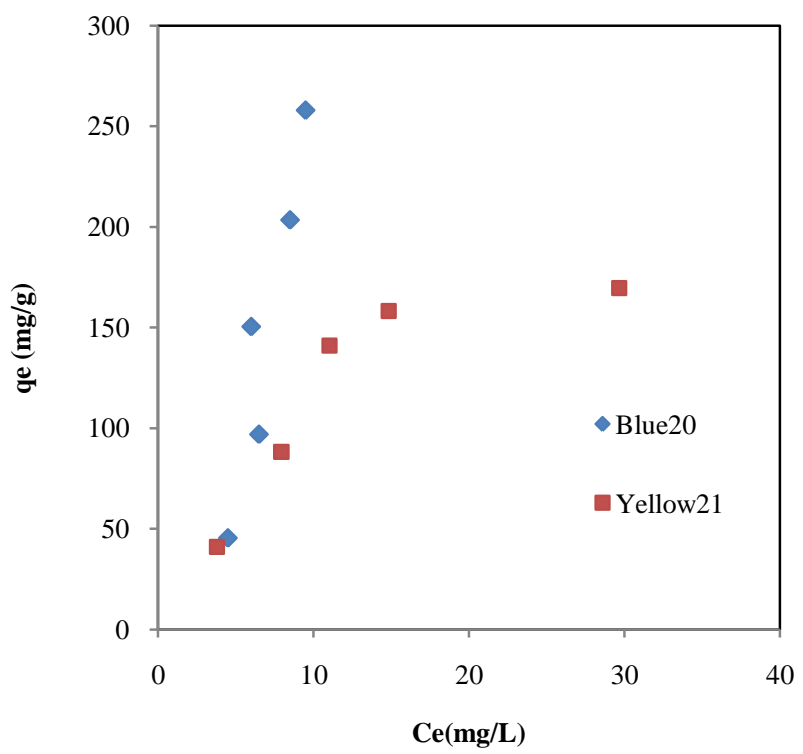

Fig. 8. Adsorption isotherm of blue21 and yellow20 from aqueous solution on organo-corn straw

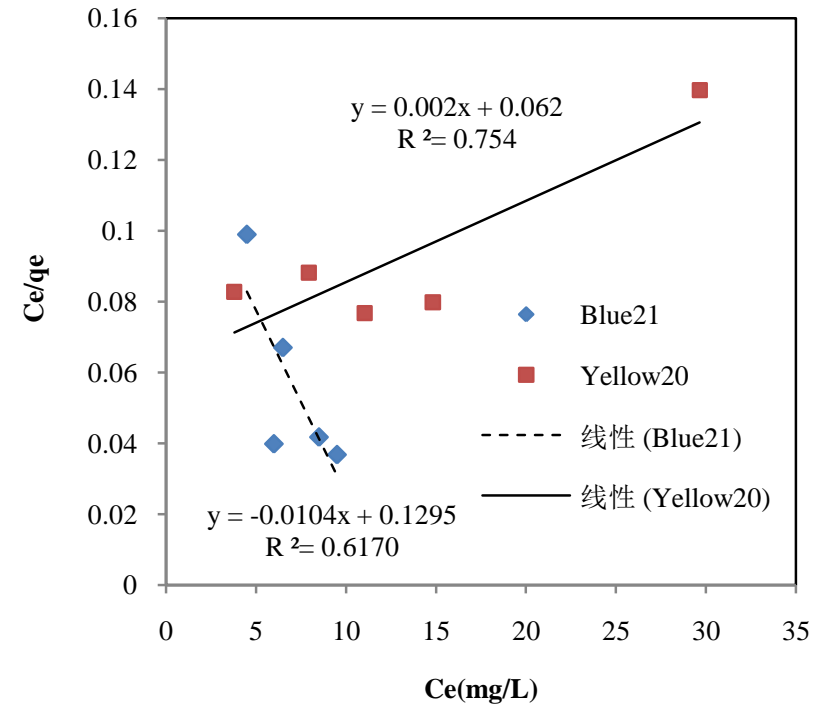

Fig. 9. Langmuir isotherm of blue 21 and yellow20 from aqueous solution using organo-corn straw

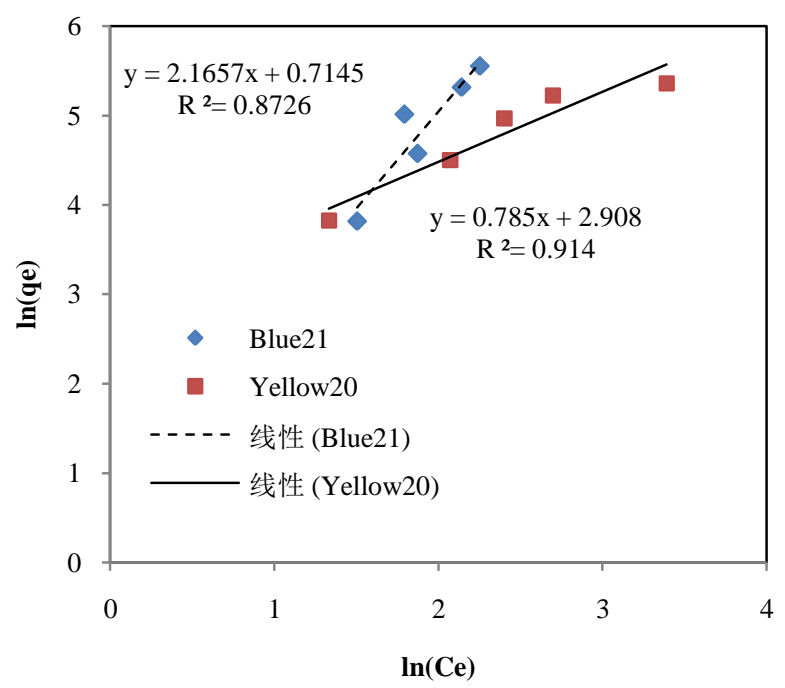

Fig. 10. Freundlich isotherm of blue 21 and yellow20 from aqueous solution using organo-corn straw 
The equilibrium data obtained were fitted to the Langmuir and Freundlich models. The isotherm constants and correlation coefficients for the adsorption of blue 21 and yellow20 onto the organo-corn straw have been listed in Table III. According to the correlation coefficients, $\mathrm{r}^{2}$, it can be seen that the system followed only the Freundlich isotherm. This suggests that the multiyear coverage on the adsorbent surface was taken place.

\section{CONCLUSION}

The modification of corn straw with surfactant can improve organic dyes such as blue 20 and yellow 21 removal from aqueous solutions. In the modification process, the surface property of the adsorbent alters from hydrophilic to hydrophobic. The lower BET surface area, replacement of the $\mathrm{O}-\mathrm{H}$ stretching or $\mathrm{H}$-bonded by the amine and the additional of $\mathrm{C}-\mathrm{C}$ bonding, change of morphology were observed in the modified adsorbent.

The adsorption ability of the organo-corn straw for the blue 21 was higher than that the yellow20. The higher carbon content of blue 21 causes higher adsorption capacity. The adsorption of the organic dyes reached the equilibrium within 180 minutes. The kinetic data conform to the pseudo-second order equation indicate forming interaction between adsorbate and adsorbent on the adsorbent surface and is the rate of limiting step and chemical sorption involved the process. The adsorption capacity of the organic dyes is hardly affected by the solution $\mathrm{pH}$ due to the dyes and their conjugate base are of hydrophobic difference. The adsorption isotherm followed Freundlich's equation showing that organic dyes molecule form multilayer on the adsorbent surface.

From the above results, the organo-corn straw is an effective adsorbent for organic dye removal from synthetic effluents.

\section{ACKNOWLEDGEMENTS}

The research was financial support by Nation Research Council of Thailand in 2012. The authors express their sincere gratitude to Mr. Niran W Stout for assistance with English translations and consultancy.

\section{REFERENCES}

[1] Y. S. Al-Degs, M. I. EI-Barghouthi, A. H. EI-Sheikh, and G. M Walker, "Effect of solution $\mathrm{pH}$, ionic strength, and temperature on adsorption behavior of reactive dyes on activated carbon," Dyes and Pigments, vol. 77, no. 1, pp. 16-23, 2008.

[2] M. A. Mohd Salleh, D. K. Mahmoud, W. A. Wan Abdul Karim, and A. Idris, "Cationic and anionic dye adsorption by agricultural solid wastes: A comprehensive review," Desalination, vol. 280, no. 1-3, pp. 1-13, 2011.

[3] R. Wibulswas, "Batch and fixed bed sorption of methylene blue on precursor and QACs modified montmorillonite," Sep. Purif. Technol., vol. 39, pp. 3-12, 2004.

[4] M. V. Sureshkumar and C. Namasivayam, "Adsorption behavior of Direct Red 12B and Rhodamine B from water onto surfactant-modified coconut coir pith," Colloids and Surfaces A: Physicochem. Eng. Aspects, vol. 317, pp. 277-283, 2008.

[5] S. Lagergren and B. K. Svenska, "About the theory of so-called adsorption of soluble substances," Vaternskapsakad Handlingar, vol. 24, no. 4, pp. 1-39, 1898

[6] Y. S. Ho and G. McKay, "Sorption of dye from aqueous solution by peat," Chem. Eng. J., vol. 70, pp. 115-124, 1998.

[7] D. D. Do, Adsorption analysis: equilibria and kinetics, Singapore, Imperial College Press, vol. 2, 1998, ch. 2, pp. 11-48.

[8] C. Umpuch, "Dye removal from household scale wastewater using montmorillonite clays," Master thesis, Dept. Chem. Eng., Suranaree University of Technology, Nakornratchasima, Thailand, 2005.

[9] J. Song, W. Zou, Y. Bian, F. Su, and R. Han, "Adsorption characteristics of methylene blue by peanut husk in batch and column modes," Desalination, vol. 265, pp. 119-125, 2011.

[10] P. Jaruwong and R. Wibulswas, "Influence of organo-clay's carbon number on the adsorption of humic acid," Asia J. Energy Environ, vol. 4, no. 1-2, pp. 41-59, 2003.

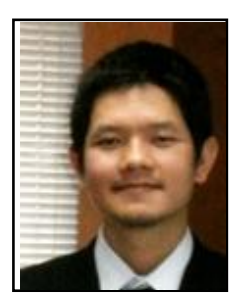

Chakkrit Umpuch recieved his B.Eng. and M.Eng. in Chemical Engineering from Suranaree University of Technology, Nakornratchasim (Thailand) in the year 2003 and 2005, respectively. He obtained a Doctoral Degree in Biotechnology and Génie des Procédés et de l'Environment in a co-supervision program between Suranaree University of Technology and Université Paul Sabatier, Toulouse, France in the year 2011. He is working as lecturer in Chemical Engineering department of Ubon Ratchathani University, Ubon Ratchathani, Thailand. His main research areas are separation processes such as adsorption technology and membrane filtration. He has published 4 papers in international journals, National journals and International conferences.

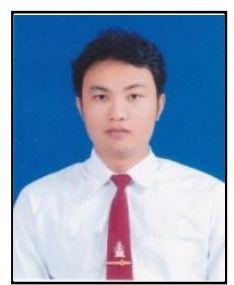

Boonsong Jutarat did his B.Eng. in Industrial Engineering and M.Eng. in Environmental Engineering from Ubon Ratchathani University, Ubon Ratchathani (Thailand) in the year 2011 and 2013, respectively. 